
\title{
CS Resarch Suare \\ Validation of Satellite-Based Sea Surface Temperature Products Against in Situ Observations Off the Western Coast of Sumatra
}

Qoosaku MOTEKI ( $\square$ moteki@jamstec.go.jp )

Japan Agency for Marine-Earth Science and Technology(JAMSTEC)

\section{Research Article}

Keywords: satellite, temperature, sea, Climate, islands, UK, Research

Posted Date: May 27th, 2021

DOI: https://doi.org/10.21203/rs.3.rs-556590/v1

License: (c) (1) This work is licensed under a Creative Commons Attribution 4.0 International License.

Read Full License

Version of Record: A version of this preprint was published at Scientific Reports on January 7th, 2022. See the published version at https://doi.org/10.1038/s41598-021-04156-0. 


\section{Abstract}

This study validated the sea surface temperature (SST) datasets from the Group for High-Resolution SST Multi Product Ensemble (GMPE), National Oceanic and Atmospheric Administration (NOAA) Optimal Interpolation (OI) SST version 2 and 2.1 (Olv2 and Olv2.1), and Estimating the Circulation and Climate of the Ocean, Phase II (ECCO2) in the area off the western coast of Sumatra against in situ observations. Furthermore, the root mean square differences (RMSDs) of Olv2, Olv2.1, and ECCO2 were investigated with respect to GMPE, whose small RMSD $<0.2 \mathrm{~K}$ against in situ observations confirmed its suitability as a reference. Although Olv2 showed a large RMSD (1-1.5 K) with a significant negative bias, Olv2.1 (RMSD $<0.4 \mathrm{~K}$ ) improved remarkably.

In the average SST distributions for December 2017, the differences among the 4 datasets were significant in the areas off the western coast of Sumatra, along the southern coast of Java, and in the Indonesian inland sea. These results were consistent with the ensemble spread distribution obtained with GMPE. The large RMSDs of Olv2 corresponded to high clouds, and it was suggested that the change in the satellites used for SST estimation contributed to the improvement in Olv2.1.

\section{Introduction}

Years of the Maritime Continent $\left(\mathrm{YMC}^{1}\right)$ is a multiyear (from 2015 to present) international program with participants from more than 15 countries. Its goal is to improve the understanding of the local oceanic and atmospheric multiscale variability of the Indo-Pacific maritime continent (MC), and the initial results have been published ${ }^{2-9}$.

Gridded gap-free objective analyses of sea surface temperature (SST), which are generally called Level 4 (L4) data, are frequently used in such studies. In addition, L4 SST datasets are conventionally used as boundary conditions in atmospheric reanalysis, climate monitoring, and weather forecasting and are widely used in studies of phenomena involving air-sea interactions, such as the Madden-Julian oscillation $\left(\mathrm{MJO}^{10}\right)$ and boreal summer intraseasonal oscillation (BSISO $\left.{ }^{11}\right)$. Understanding the characteristics of and differences in the various L4 SST datasets in the vicinity of the MC is very important as a premise for summarizing the various results of YMC.

Many L4 SST datasets have distinct characteristics depending on the assimilation methods adopted, the choice of satellites, the number of in situ observations, and the temporal-spatial resolution, and the differences in values and distributions among datasets can be misleading in discussions summarizing many YMC results. In particular, the validation of L4 SST in shallow coastal sea areas is difficult because there are very few in situ SST observations with buoys and Argo floats, although errors in satellite estimations easily increase near coasts and marginal seas with small islands.

Therefore, we need to understand the characteristics of L4 SST datasets in a specific region for a specific period apart from the validation, which is generally performed as a global average or over a longer period by the dataset providers. The L4 SST Quality Monitor (L4-SQUAM) system is aimed at cross-comparisons 
of various L4 products and monitors the quality of various L4 products globally in near-real time by comparison with the Group for High-Resolution SST Multi Product Ensemble (GMPE ${ }^{12,13}$ ). GMPE is provided on a daily basis by the UK Met Office, taking $16 \mathrm{~L} 4$ products as inputs and producing an ensemble median and standard deviation with a $1 / 4^{\circ} \mathrm{grid}^{13}$. With respect to near-surface Argo float observations, GMPE is globally more reasonable than any of the contributing SST products, with a standard deviation error of $0.40 \mathrm{~K}$.

However, confirming the suitability of GMPE is necessary because the observation frequency of in situ SST by Argo is approximately once every 10 days, and the number of Argo floats is very small in shallow coastal sea areas. This study verifies the L4 SST datasets, including GMPE, in the area off the western coast of Sumatra against in situ water temperature values at $10 \mathrm{~m}$ depth obtained from the Sumatra buoy $\left(5^{\circ} \mathrm{S}, 100^{\circ} \mathrm{E}\right)$ during the YMC period and conductivity-temperature-depth (CTD) profiles obtained by the Research Vessel (R/V) Mirai (fixed at $4.24^{\circ} \mathrm{S}, 101.52^{\circ} \mathrm{E}$ for the period of $5 \mathrm{Dec}$. 2017- 1 Jan. 2018) during the cruise named MR17-08 ${ }^{14}$. The National Oceanic and Atmospheric Administration (NOAA) Optimal Interpolation (OI) SST version 2 (Olv2) is one of the most popular L4 datasets and has been widely used in many studies. On 1 Apr. 1 2020, version 2.1 of NOAA OI SST (Olv2.1) was published. Furthermore, we chose the Estimating the Circulation and Climate of the Ocean, Phase II (ECCO2), as a verification target product based on a three-dimensional (3D) ocean model. In 3D ocean objective analysis, such as ECCO2, SST is not only constrained by satellite and in situ observations but also affected by the dynamic ocean velocity field. This study summarizes the characteristics of the four L4 SST datasets, which are estimated as so-called "bulk" SST off the western coast of Sumatra during the YMC period.

\section{Methods}

\section{In situ observations}

In this study, the following two in situ observation stations in the marginal sea off the western coast of Sumatra were used for validation. The Sumatra buoy was deployed at $5^{\circ} \mathrm{S}, 100^{\circ} \mathrm{E}$ (approximately $270 \mathrm{~km}$ from the western coast of Sumatra) as a mission of the R/V Mirai MR17-08 cruise. Hourly water temperature profiles were obtained from 5 Dec. 2017 to 10 Dec. 2018 (observations stopped due to communication trouble).

During the R/V Mirai MR17-08 cruise period of 6 Dec. 2017-1 Jan. 2018, CTD observations were conducted 8 times per day, every 3 hours, at the fixed point of $4.24^{\circ} \mathrm{S}, 101.52^{\circ} \mathrm{E}$ (approximately $100 \mathrm{~km}$ from the western coast of Sumatra). Here, we use the 1-day average water temperature from Sumatra buoy and the CTD profiles at $10 \mathrm{~m}$ depth as a reference for SST. As a result of examining the different depths between 1 and $10 \mathrm{~m}$, the values of each index shown in this study (RMSD, TC, RC, and variance) do not change much. 
For the observational errors of the Sumatra buoy and CTD, the expected measurement error is $\pm 0.001{ }^{\circ} \mathrm{C}$ according to the manufacturing datasheet ${ }^{17}$. The time representative error within 24 hours estimated from the variance of fluctuations is estimated to be $0.03 \mathrm{~K}$ on average and $0.28 \mathrm{~K}$ at maximum. Although the spatial representative error could vary depending on the current velocity, the maximum travel distance for 24 hours assuming $0.3 \mathrm{~m} / \mathrm{s}$ is approximately $26 \mathrm{~km}(0.3 \mathrm{~m} / \mathrm{s} \times 24$ hours $\times 3600$ seconds), which almost corresponds to the horizontal size of the $1 / 4^{\circ} \mathrm{grid}$. The estimated horizontal representative error of the targeted daily SST products with a $1 / 4^{\circ}$ grid is $0.03 \mathrm{~K}$ on average and $0.28 \mathrm{~K}$ at maximum.

\section{Validated target SST products}

Although there are many L4 SST datasets, we chose the following 4 widely used datasets with a spatial resolution of $0.25^{\circ}$ and daily temporal resolution to be validated with the YMC in situ SST observations. GMPE is the ensemble median of 16 L4 SST datasets provided by the Copernicus Marine Environment Monitoring Service (CMEMS) for the period from 16 Sep. 2017 to the present ${ }^{13}$. Olv2, including data from 1 Sep. 1981 to 26 Apr. $2020^{18}$, is one of the most popular daily L4 SST datasets and has been widely used in many studies. On 1 Apr. 2020, Olv2.1 was released as an update to Olv2; data are available from 1 Sep. 1981 onward $^{16,19}$. Major improvements from Olv2 to Olv2.1 include 1) large increases in the number of in situ ships, buoys, and Argo floats used and 2) the use of satellite inputs from METOP-A and NOAA-19 to METOP-A and METOP-B to remove degraded satellite data ${ }^{19,20}$. The ECCO2 dataset has 50 vertical levels at a maximum model depth of $6150 \mathrm{~m}$ with a high global ocean resolution of $0.25^{\circ} \times$ $0.25^{\circ 21,22}$. ECCO2 is an adjoint method-based state estimation constrained to the available satellite (SST and SSH) and in situ (vertical temperature and salinity profiles) data, is available from 16 Sep. 1992, and is updated with a few months' delay. Note that the difference in the correlation length scales between datasets could affect the representation of the SST distribution. The horizontal correlation length scales of Olv2, Olv2.1, and ECCO2 would be approximately 150-200 km, although the correlation length scale of the GMPE system could be approximately $100 \mathrm{~km}$ in the tropics (e.g., $\left.{ }^{23}\right)$.

The sea surface geostrophic current calculated from the SSH of the Data Unification and Altimeter Combination System (DUACS) multimission gridded (L4) altimeter products with a spatial resolution of $0.25^{\circ}$ and daily temporal resolution ${ }^{24,25}$ was used. In addition, the daily estimates of OLR with a $2.5^{\circ}$ resolution from polar-orbiting satellites ${ }^{26}$ were provided by NOAA to confirm convective activities.

\section{Results}

\section{Validation for the years 2017-2019}

Figure 1 shows scatter plots between SST datasets, and temporally averaged indices are summarized in Table 1. First, the GMPE and the Sumatra buoy for the period 6 Dec. 2017-30 Nov. 2018 are compared in Fig. 1a. GMPE is very consistent with the in situ observations (a temporally averaged RMSD of $0.17 \mathrm{~K}$, time correlation (TC) of 0.95 , regression coefficient (RC) of 1.0 , and variance of $0.15 \mathrm{~K}$ ). Near the shallow coastal sea (approximately $1000 \mathrm{~m}$ depth), short-term (within a week) fluctuations in the ocean current 
direction due to coastal tides and eddies were observed ${ }^{14}$. As shown in Table 1, the TC and RC values against the Mirai CTD were smaller than those in the open ocean at the Sumatra buoy. These values show that the use of GMPE as a reference is reasonable in the area off the western coast of Sumatra. The indices of Olv2 (Fig. 1b) off the western coast of Sumatra are the worst among the selected L4 datasets. The large RMSD is due to a large negative bias. Although Olv2.1 (Fig. 1c) shows a negative bias, it is significantly improved from Olv2. However, the TC value is low, and the variance is still large in the shallow coastal sea. The RMSD of ECCO2 (Fig. 1d) is due to a positive bias, and ECCO2 shows an overestimation trend for low SSTs less than $29^{\circ} \mathrm{C}$. Notably, the variance is quite small, and the TC value is higher than that of Olv2.1.

Table 1

The root mean squared difference (RMSD), time correlation (TC), regression coefficient (RC), and variance of GMPE, Olv2, Olv2.1, and ECCO2 with respect to the Sumatra buoy $\left(5^{\circ} \mathrm{S}, 100^{\circ} \mathrm{E}\right)$ averaged for 6 Dec. 2017-30 Nov. 2018 [R/V Mirai CTD $\left(4^{\circ} \mathrm{S}, 101^{\circ} \mathrm{E}\right)$ averaged for 6-31 Dec. 2017].

\begin{tabular}{|lllll|}
\hline L4 SST dataset & RMSD (K) & TC & RC & Variance (K) \\
\hline GMPE & $0.16[0.07]$ & $0.94[0.60]$ & $1.10[0.46]$ & $0.16[0.05]$ \\
\hline Olv2 & $0.93[1.43]$ & $0.51[0.46]$ & $0.51[2.16]$ & $0.56[0.40]$ \\
\hline Olv2.1 & $0.33[0.42]$ & $0.83[0.22]$ & $0.83[0.83]$ & $0.29[0.39]$ \\
\hline ECCO2 & $0.37[0.49]$ & $0.87[0.35]$ & $0.75[0.17]$ & $0.17[0.04]$ \\
\hline
\end{tabular}

Figure 2a shows the RMSD distribution of Olv2 with respect to GMPE averaged for the period of 16 Sep. 2017-31 Dec. 2019. The large RMSD of Olv2 is not localized in the area off the western coast of Sumatra, and the RMSD of $0.5-1 \mathrm{~K}$ is widely distributed in the eastern Indian Ocean, especially in the Southern Hemisphere from $0-30^{\circ} \mathrm{S}$. Focusing on the tropics from $15^{\circ} \mathrm{S}-15^{\circ} \mathrm{N}$, areas with large RMSD are seen in the coastal regions off western Africa, South America, and northern Australia, which could correspond to coastal upwelling regions. Over the Indian Ocean, multiple areas with large RMSD are distributed in the western, central, and eastern parts. These areas with large RMSD would be a significant issue when summarizing various results that use different L4 SST datasets. For example, different SST datasets could lead to different processes, results, and theories, even for the same phenomenon.

Figure $2 \mathrm{~b}$ shows the time series for the RMSDs of Olv2, Olv2.1, and ECCO2 with respect to GMPE averaged for the area from $3-8^{\circ} \mathrm{S}, 95-105^{\circ} \mathrm{E}$, where diurnal convection originating from Sumatra propagates ${ }^{15}$; this region is the main target area for air-sea interaction research related to YMC. The verification target area is selected because the suitability of the L4 SST datasets has a large impact as a premise for various YMC studies. Although Olv2 repeatedly shows peaks that exceed $1 \mathrm{~K}$ and last for 1 week -1 month, the RMSD of Olv2.1 is generally less than $0.5 \mathrm{~K}$ throughout the entire period. The RMSD of ECCO2 has a peak around Oct. each year associated with the seasonal variation in the large meridional gradient of SST from $3-8^{\circ} \mathrm{S}$. The RMSD variation in ECCO2 occurs because the position of the large SST gradient in ECCO2 is shifted from that in GMPE. 


\section{Validation for Dec. 2017 during the period of the MR17-08 cruise}

Figure 3 shows the time series of SST (a-b) at the Sumatra buoy and in the fixed-point R/V Mirai CTD profiles during the MR17-08 cruise from 6 Dec. -31 Dec. 2017. The in situ observed SST variation is smaller than approximately $1 \mathrm{~K}$ because the mixed layer was well developed (80-120 $\mathrm{m}$ in depth). The mixed layer deepening could have been due to the strong westerly winds (5-10 m/s) that were dominant after the MJO passage. Olv2 shows a large negative bias for the entire period of the MR17-08 cruise, and its variation is quite different from that of the in situ SST. Olv2.1 is much improved in terms of temporal variations, although it still has a negative bias with respect to the Sumatra buoy. In addition, Olv2.1 still has some negative bias after 17 Dec., although it is very consistent with the R/V Mirai CTD data before 17 Dec. ECCO2 shows a positive bias, and its variation amplitude is smaller than that of the in situ observations.

Figure 4 shows the average SST distributions of GMPE, Olv2, Olv2.1, and ECCO2 for Dec. 2017. During this period, which includes the MR17-08 cruise, there are remarkable differences in the SST distributions in the area off the western coast of Sumatra in the Southern Hemisphere. In the Olv2 distribution (Fig. 4b), low SSTs less than $28^{\circ} \mathrm{C}$, which are clearly different from those of GMPE, are distributed off the western coast of Sumatra and extend to the equator from the south. The large RMSDs of Olv2 exceeding $1 \mathrm{~K}$ are distributed in the area off the western coast of Sumatra, the southern coast of Java, and the inland sea between the islands of Borneo and Java. As mentioned on the website providing Olv2 and Olv2. $1^{16}$, the quality of the satellite data used in Olv2 may be degraded in such areas, for example, due to the continuous existence of deep convection. In the distribution of Olv2.1 (Fig. 4c), the unrealistically low SST in Olv2 is corrected in many areas, although the RMSD of approximately $0.4 \mathrm{~K}$ due to the unrealistically low SST off the western coast of Sumatra partly remains. Over the open ocean of the Indian Ocean, the RMSD of Olv2.1 is generally less than $0.2 \mathrm{~K}$, and Olv 2.1 basically presents a distribution that is very similar to that of GMPE. Focusing on the SST front, as indicated by the contours of 28.4$28.8^{\circ} \mathrm{C}$, the distribution of ECCO2 (Fig. $4 \mathrm{~d}$ ) is more similar to that of GMPE than to that of Olv2, although a positive bias with respect to GMPE is seen in the vicinity of the MC. Although Moteki et al. ${ }^{4}$ showed that ECCO2 data has a positive bias off the coast of western Sumatra, we found here that the explanation for several large RMSDs of $0.4-1.2 \mathrm{~K}$ with positive bias is the difference between the magnitude of the meridional SST gradient from $6-10^{\circ} \mathrm{S}$ and that of GMPE.

Figure 5 depicts SST, SSH, the sea surface geostrophic current calculated from SSH, and outgoing longwave radiation (OLR) on $13 \mathrm{Dec}$. 2017. The area with large RMSDs exceeding $1 \mathrm{~K}$ corresponds well to OLRs less than $240 \mathrm{~W} / \mathrm{m}^{2}$. This fact suggests that a large-scale convective system developing continuously over the $\mathrm{MC}$ is one of the factors contributing to the quality degradation of Olv2, as indicated by its large RMSD with respect to GMPE. Note that the RMSD of Olv2 does not have a simple proportional relationship with OLRs; thus, their variations do not correlate with each other. The ensemble spread of the 16 datasets used in GMPE shows that the estimated errors of $0.3-0.5 \mathrm{~K}$, which are larger 
than those of globally averaged values shown in previous reports (e.g., ${ }^{12,13}$ ), are distributed in the area to the north of $6^{\circ} \mathrm{S}$ off the western coast of Sumatra, although large estimated errors exceeding $0.5 \mathrm{~K}$ are found in the area to the south of $6^{\circ} \mathrm{S}, 95-115^{\circ} \mathrm{E}$. The large RMSD of Olv2 in the area off the western coast of Sumatra is considered to be caused by inherent problems in the Olv2 estimation process.

Olv2.1 is significantly improved from Olv2 over the whole tropical eastern Indian Ocean. There are several large RMSDs in Olv2.1 exceeding $1 \mathrm{~K}$ in the areas off the southern edge of Sumatra $\left(5-8^{\circ} \mathrm{S}, 102-105^{\circ} \mathrm{E}\right)$, along the eastern edge of the eddy off the southern coast of Java $\left(10-15^{\circ} \mathrm{S}, 105-110^{\circ} \mathrm{E}\right)$, and in the inland sea $\left(0-4^{\circ} \mathrm{S}, 107-109^{\circ} \mathrm{E}\right)$.

Because the SST of ECCO2 is estimated after dynamically considering the ECCO2-estimated ocean current, the estimated error of the ECCO2 ocean current is one of the main factors causing the ECCO2 SST error. There are some shifts in position and size between the eddies obtained with ECCO2 and observed SSH to the south of $10^{\circ} \mathrm{S}$, and these shifts are considered to be a factor causing the large RMSD of ECCO2 SST in the vicinity of the eddies.

In summary, YMC, a multiyear (from 2015 to present) international program with participants from more than 15 countries, is being conducted. Understanding the characteristics of and differences in SST datasets in the vicinity of the $\mathrm{MC}$ is very important as a premise for discussion. This study validated the L4 SST datasets of GMPE, Olv2, Olv2.1, and ECCO2 in the area off the western coast of Sumatra against in situ observations.

GMPE is the most reasonable L4 SST dataset according to validation with Argo floats worldwide. GMPE shows very small RMSD $<0.2 \mathrm{~K}$ according to validation with the Sumatra buoy and R/V Mirai CTD data obtained during the MR17-08 cruise, even in the area near the western coast of Sumatra. Although the RMSD of Olv2 off the western coast of Sumatra is very large (1-1.5 K) and associated with a significant negative bias, that of Olv2.1 is improved (RMSD $<0.4 \mathrm{~K}$ ) in many areas. The RMSD of ECCO2 is less than $0.4 \mathrm{~K}$ and associated with a positive bias. Notably, ECCO2 shows a slightly higher TC than Olv2.1.

Among the RMSD results of the Olv2 distribution with respect to the GMPE reference, large RMSDs were found to be widely distributed across the eastern Indian Ocean rather than representing a local feature off the western coast of Sumatra. Multiple areas with large Olv2 RMSD (0.5-1 K) were distributed in the western, central and eastern regions of the Indian Ocean. These large RMSDs indicate a serious problem that can affect interpretations when conducting various analyses and numerical experiments related to YMC. Atmospheric simulation results can vary significantly depending on the choice of SST dataset.

In areas of the Northern Hemisphere and to the east of $115^{\circ} \mathrm{E}$, the monthly averaged SST distributions of the 4 SST datasets were generally similar to each other. However, there were significant differences between the datasets in the areas off the western coast of Sumatra, the southern coast of Java, and the Indonesian inland sea. This feature was consistent with the ensemble spread distribution from GMPE. Although low SSTs less than $28^{\circ} \mathrm{C}$, which were clearly different from those of GMPE, were located off the western coast of Sumatra and extended to the equator from the south in Olv2, this distribution was 
improved in Olv2.1. The area with large RMSDs corresponded well to the continuous occurrence of deep convection. Changes in the satellite data used for estimation were suggested to have contributed to the improvement in Olv2.1.

\section{Declarations}

\section{Acknowledgements}

The authors acknowledge members of the Japan Agency for Marine-Earth Science and Technology (JAMSTEC)/Dynamic Coupling of Ocean-Atmosphere-Land Research Program (DCOP) for their valuable suggestions.

\section{Author contributions}

Q. M. designed the study, analyzed the data, and wrote the manuscript.

\section{Competing interests}

The author declares no competing interests.

\section{References}

1. Yoneyama, K. \& Zhang, C. Years of the maritime continent. Geophys. Res. Lett. 47, e2020GL087182 (2020).

2. Kinoshita, T. et al. A study of gravity wave activities based on intensive radiosonde observations at Bengkulu during YMC-Sumatra 2017. IOP Conf. Ser. Earth Environ. Sci. 303, 012011 (2019).

3. Katsumata, M., Taniguchi, K. \& Nishizawa, T. An attempt to retrieve continuous water vapor profiles in marine lower troposphere using shipboard Raman/Mie lidar system. SOLA. 16A, 6-11 (2020).

4. Moteki, Q., Katsumata, M., Yoneyama, K., Ando, K. \& Hasegawa, T. Drastic thickening of the barrier layer off the western coast of Sumatra due to the Madden-Julian oscillation passage during the preyears of the maritime continent campaign. Prog. Earth Planet. Sci. 5, 35 (2018).

5. Yokoi, S. et al. Diurnal cycle of precipitation observed in the western coastal area of Sumatra Island: offshore preconditioning by gravity waves. Mon. Weather Rev. 145, 3745-3761 (2017).

6. Yokoi, S., Mori, S., Syamsudin, F., Haryoko, U. \& Geng, B. Environmental conditions for nighttime offshore migration of precipitation area as revealed by in situ observation off Sumatra Island. Mon. Weather Rev. 147, 3391-3407 (2019).

7. Yokoi, S. Diurnal variation of surface heat fluxes off the west coast of Sumatra Island as revealed by in situ observation. SOLA. 16A, 1-5 (2020).

8. Wu, P., Ardiansyah, D., Mori, S. \& Yoneyama, K. The effect of an active phase of the Madden-Julian oscillation on surface winds over the western coast of Sumatra Island. IOP Conf. Ser. Earth Environ. Sci. 303, 012009 (2019). 
9. Zhao, N. \& Nasuno, T. How does the air-sea coupling frequency affect convection during the MJO passage? J. Adv. Model. Earth Syst. 12, e2020MS002058 (2020).

10. Madden, R. A. \& Julian, P. R. Description of Global-Scale Circulation Cells in the Tropics with a 40-50 Day Period. J. Atmospheric Sci. 29, 1109-1123 (1972).

11. Wang, B. \& Xie, X. A Model for the Boreal Summer Intraseasonal Oscillation. J. Atmospheric Sci. 54, 72-86 (1997).

12. Dash, P., Ignatov, A., Kihai, Y. \& Sapper, J. The SST quality monitor (SQUAM). J. Atmos. Ocean. Technol. 27, 1899-1917 (2010).

13. Martin, M. et al. Group for high resolution sea surface temperature (GHRSST) analysis fields intercomparisons. Part 1: a GHRSST multi-product ensemble (GMPE). Deep Sea Res. II Top. Stud. Oceanogr. 77-80, 21-30 (2012).

14. JAMSTEC \& BPPT. MR17-08 Cruise Report http://www.godac.jamstec.go.jp/catalog/data/doc_catalog/media/MR17-08_leg1-2_all.pdf (2018).

15. Mori, S. et al. Diurnal land-sea rainfall peak migration over Sumatera Island, Indonesian maritime continent, observed by TRMM satellite and intensive rawinsonde soundings. Mon. Weather Rev. 132, 2021-2039 (2004).

16. NOAA. Optimum Interpolation Sea Surface Temperature (OISST) v2.1 https://www.ncdc.noaa.gov/oisst/optimum-interpolation-sea-surface-temperature-oisst-v21 (2020).

17. Sea Bird Scientific. SBE 911p/us CTD https://www.seabird.com/profiling/sbe-911plus-ctd/familydownloads? productCategoryld=54627473769 (2021).

18. Banzon, V., Smith, T. M., Chin, T. M., Liu, C. \& Hankins, W. A long-term record of blended satellite and in situ sea-surface temperature for climate monitoring, modeling and environmental studies. Earth Syst. Sci. Data. 8, 165-176 (2016).

19. Huang, B. et al. Improvements of the daily optimum interpolation sea surface temperature (DOISST) version 2.1. J. Clim. 34, 2923-2939 (2021).

20. Banzon, V., Smith, T. M., Steele, M., Huang, B. \& Zhang, H. M. Improved estimation of proxy sea surface temperature in the Arctic. J. Atmos. Ocean. Technol. 37, 341-349 (2020).

21. Halpern, D., Menemenlis, D. \& Wang, X. Impact of data assimilation on ECCO2 equatorial undercurrent and north equatorial countercurrent in the Pacific ocean. J. Atmos. Ocean. Technol. 32, 131-143 (2015).

22. Menemenlis, D. et al. ECCO2: High Resolution Global Ocean and Sea Ice Data Synthesis https://www.mercator-ocean.fr/wp-content/uploads/2015/06/lettre_31_en.pdf\#page=13 (2008).

23. De Meyer, V. \& Roca, R. Thermodynamic scaling of extreme daily precipitation over the tropical ocean from satellite observationsthermodynamic scaling of extreme daily precipitation over the tropical ocean from satellite observations. J. Meteorol. Soc. Jpn. II. 99, 423-436 (2021).

24. Pujol, I. et al. DUACS DT2014: the new multi-mission altimeter data set reprocessed over 20 years. Ocean Sci. 12, 1067-1090 (2016). 
25. Pujol, M. I. et al. Gauging the improvement of recent mean sea surface models: a new approach for identifying and quantifying their errors. J. Geophys. Res.: Oceans. 123, 5889-5911 (2018).

26. Gruber, A. \& Krueger, A. F. The status of the NOAA outgoing longwave radiation data set. Bull. Am. Meteorol. Soc. 65, 958-962 (1984).

\section{Figures}

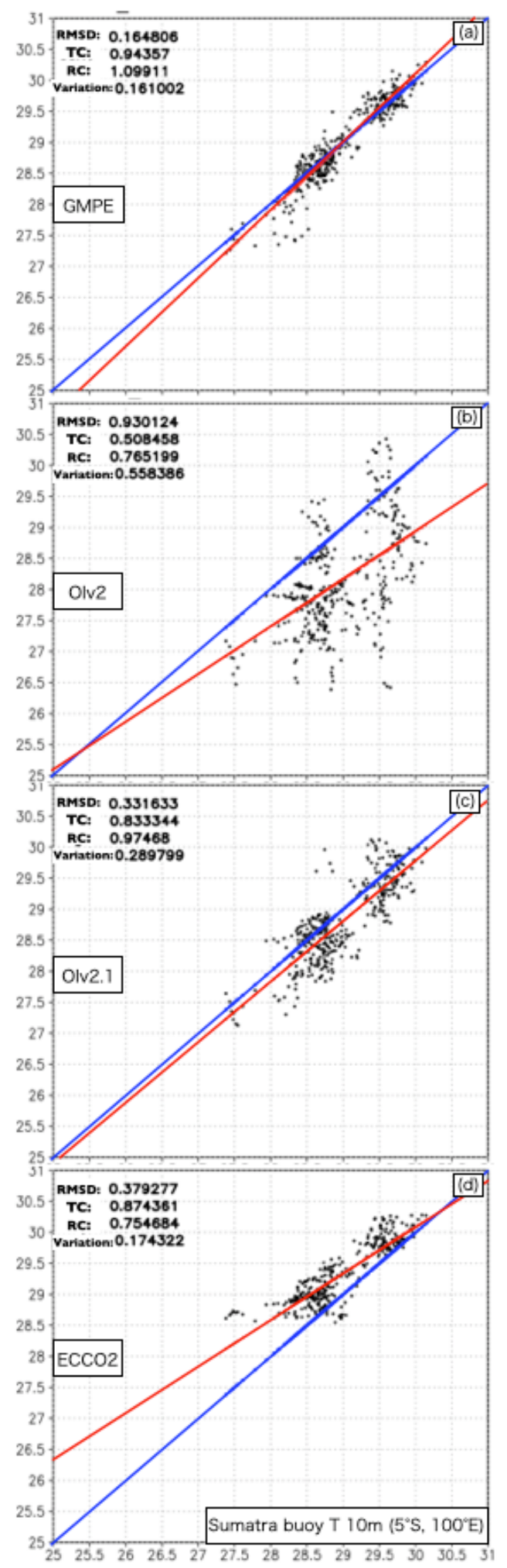


Figure 1

Scatter plots for (a) GMPE, (b) Olv2, (c) Olv2.1, and (d) ECCO2 at $5^{\circ} \mathrm{S}, 100^{\circ} \mathrm{E}$ for the period from 6 Dec. 2017 - 30 Nov. 2018 with respect to the Sumatra buoy. The temporally averaged RMSD, TC, RC, and variance are shown in the top left corner of each panel. The regression line and the line with a slope of 1 are shown by the red and blue lines, respectively.
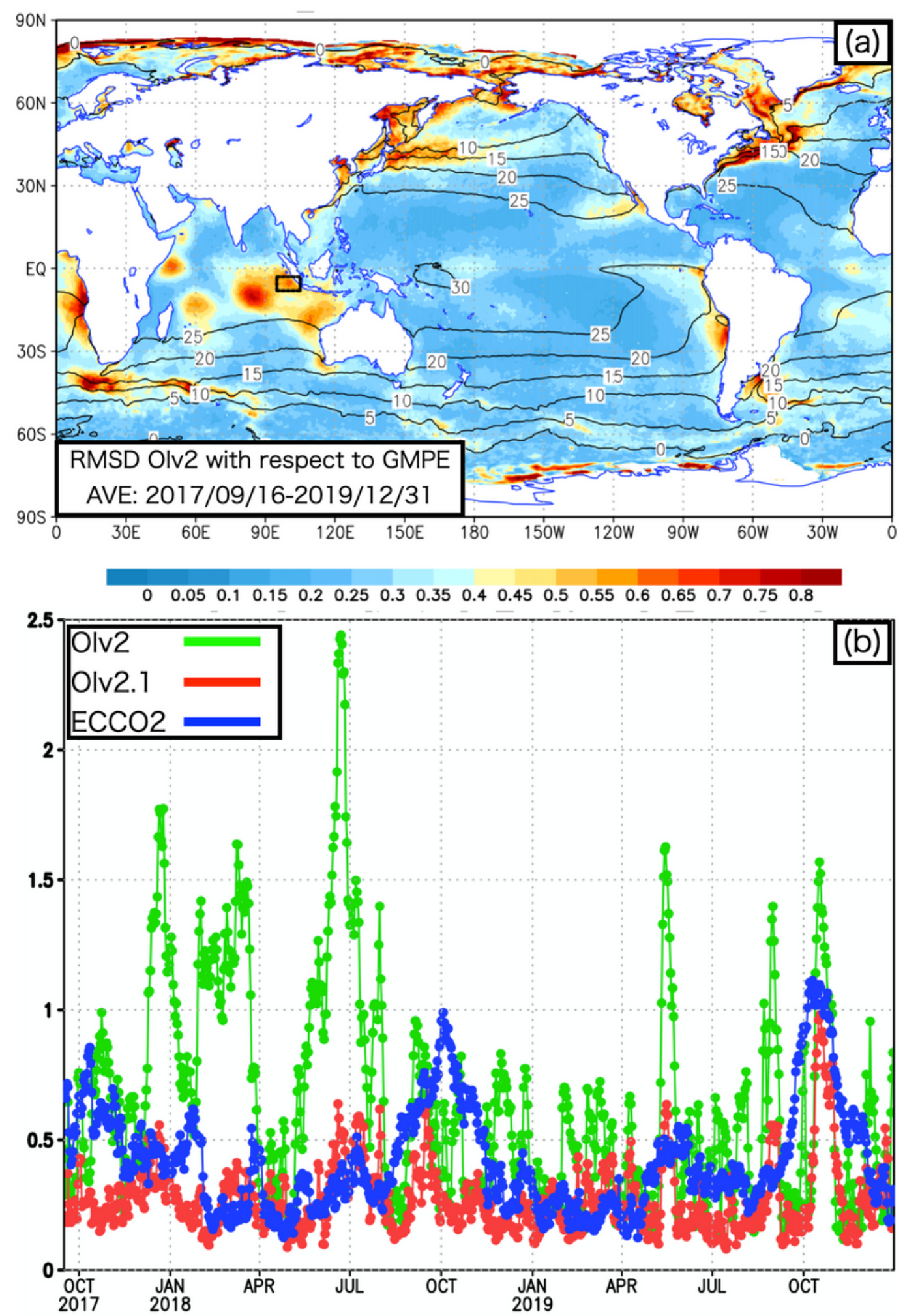

Figure 2 
(a) RMSD of Olv2 with respect to GMPE (color) and SST with GMPE (contour) for the period from 1 Dec. 2017 - 31 Dec. 2019. (b) Time series of area-averaged RMSD with respect to GMPE for the period from 16 Sep. 2017 - 31 Dec. 2019. Olv2, Olv2.1, and ECCO2 are shown in green, red, and blue, respectively. Note: The designations employed and the presentation of the material on this map do not imply the expression of any opinion whatsoever on the part of Research Square concerning the legal status of any country, territory, city or area or of its authorities, or concerning the delimitation of its frontiers or boundaries. This map has been provided by the authors.
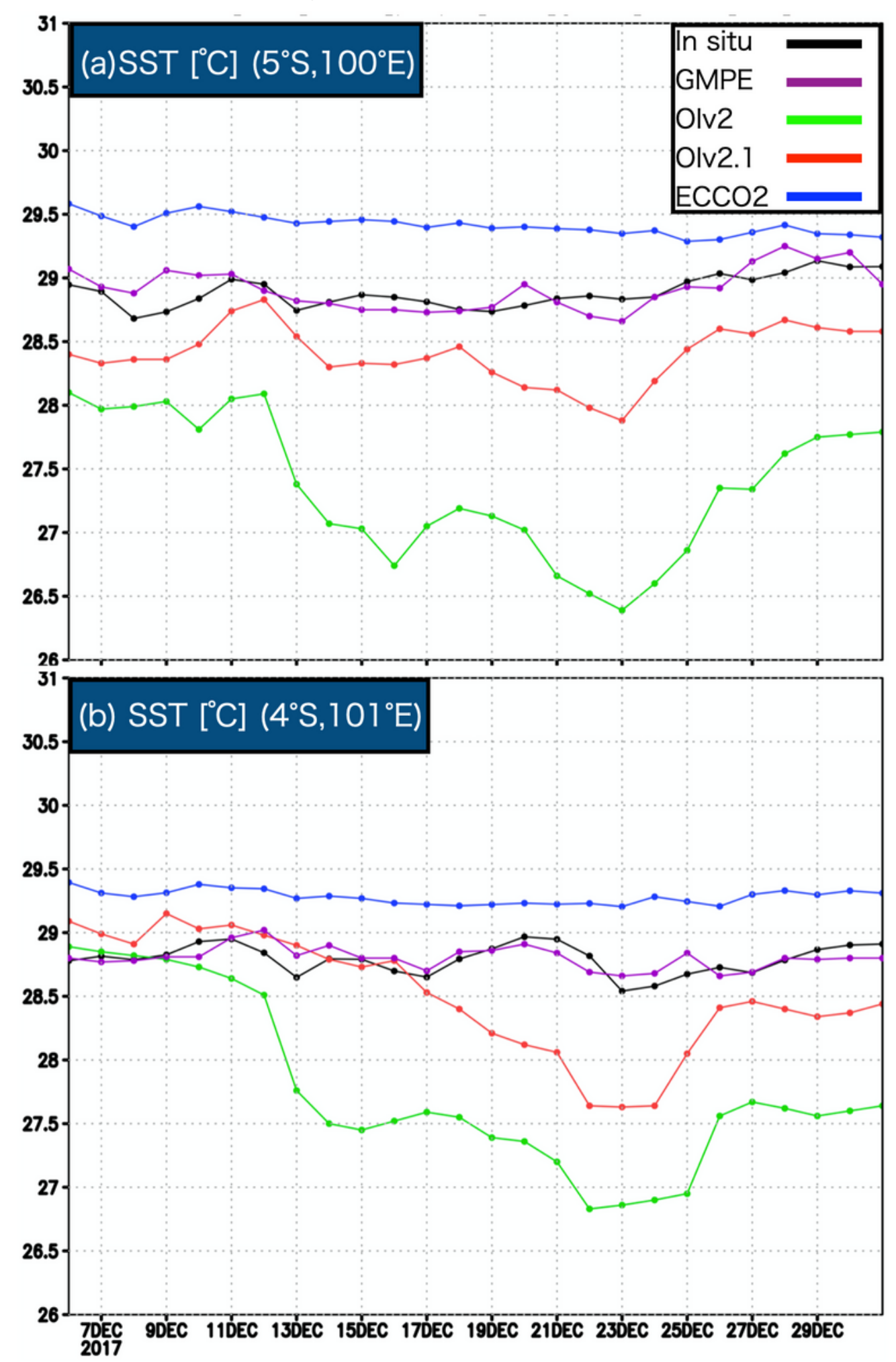
Figure 3

Daily SST variations obtained with respect to (a) the Sumatra buoy $\left[5^{\circ} \mathrm{S}, 100^{\circ} \mathrm{E}\right]$ and (b) R/V Mirai CTD data [ $\left.4^{\circ} \mathrm{S}, 101^{\circ} \mathrm{E}\right]$ (black) from GMPE (purple), Olv2 (green), Olv2.1 (red), and ECCO2 SST (blue).
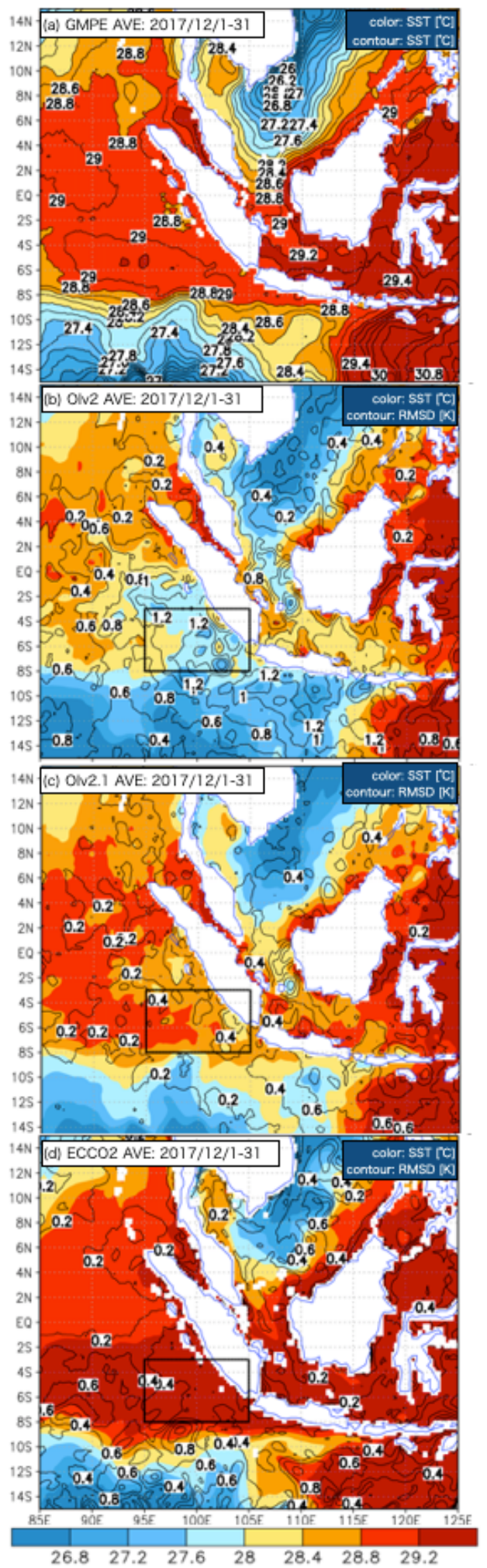

Figure 4 
(a) GMPE (color and contours every $0.2 \mathrm{~K}$ ), (b) Olv2, (c) Olv2.1, and (d) ECCO2 for 1-31 Dec. 2017. The RMSD with respect to GMPE is indicated with contours every $0.2 \mathrm{~K}$ in (b)-(d). Spatial correlation and regression values with respect to GMPE calculated for the box from 3-8 ${ }^{\circ} \mathrm{S} 95-105^{\circ} \mathrm{E}$ are shown at the top right corner of each panel in (b)-(d). Note: The designations employed and the presentation of the material on this map do not imply the expression of any opinion whatsoever on the part of Research Square concerning the legal status of any country, territory, city or area or of its authorities, or concerning the delimitation of its frontiers or boundaries. This map has been provided by the authors.

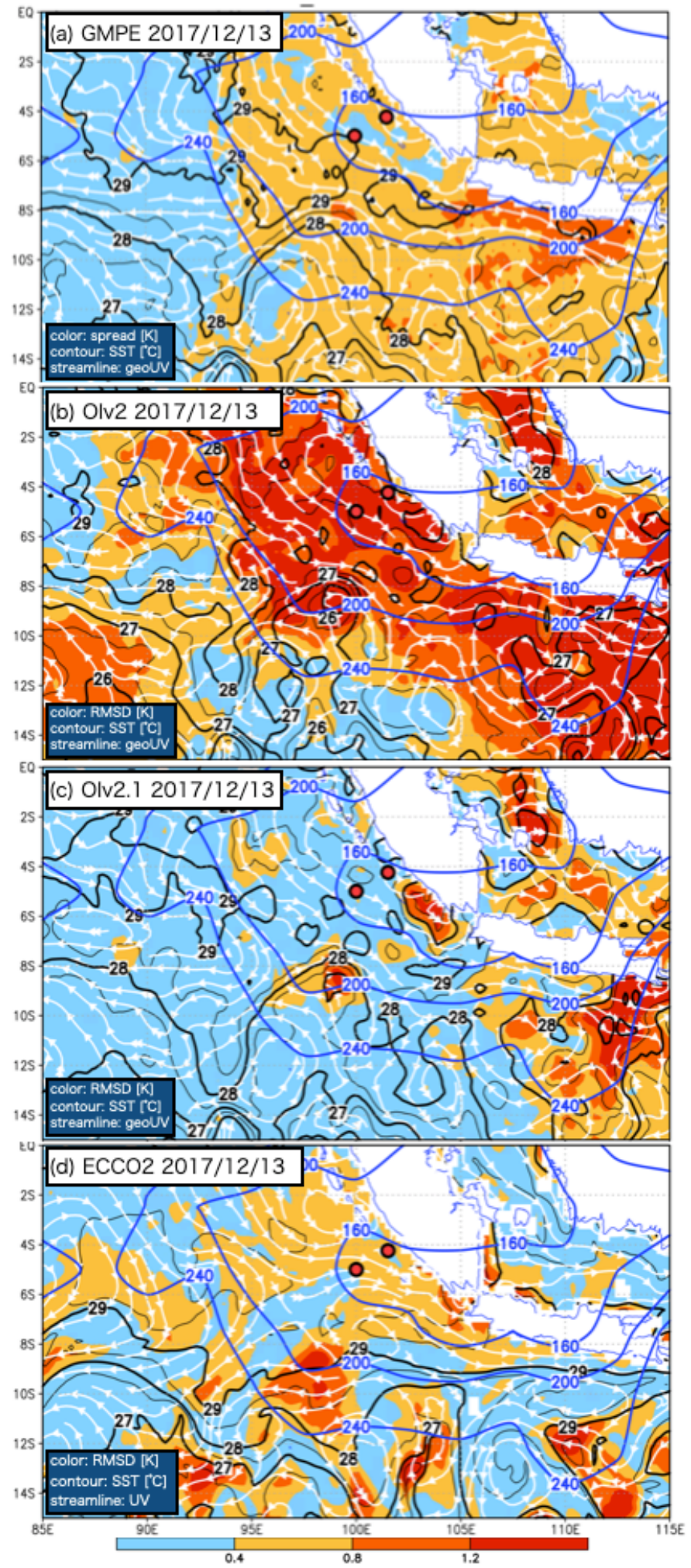




\section{Figure 5}

The estimated error (colored) as the (a) GMPE ensemble standard deviation, (b) RMSD of Olv2 with respect to GMPE, (c) RMSD of Olv2.1 with respect to GMPE, and (d) RMSD of ECCO2 with respect to GMPE on $13 \mathrm{Dec}$. 2017. The black contours (every $0.5 \mathrm{~K}$ is indicated with thin contours, and every $1 \mathrm{~K}$ is indicated with bold contours) show SST from (a) GMPE, (b) Olv2, (c) Olv2.1, and (d) ECCO2. The white streamlines indicate the surface current from (a)-(c) the geostrophic current calculated from SSH and (d) ECCO2. The blue contours show 160,200 , and $240 \mathrm{~W} / \mathrm{m} 2$ OLR. The two red circles indicate the locations of the Sumatra buoy and R/V Mirai CTD. Note: The designations employed and the presentation of the material on this map do not imply the expression of any opinion whatsoever on the part of Research Square concerning the legal status of any country, territory, city or area or of its authorities, or concerning the delimitation of its frontiers or boundaries. This map has been provided by the authors. 